\title{
Massage Therapy: Intervention Frequency and Cost Survey (IFACS) Data with Policy Implications for Nonpharmacologic Treatment of Chronic Pain
}

\begin{abstract}
Participants completing a 52-week efficacy and dosing randomized clinical trial (RCT) of massage therapy for knee pain due to osteoarthritis (OA) were invited to complete the Intervention Frequency and Cost Survey (IFACS), a web-based, validated instrument for collecting actual and ideal willingness to pay and treatment frequency data from the patient's perspective. Of those contacted ( $\mathrm{n}=179), 117$ completed the survey ( $65 \%$ response rate). Although $95 \%$ of respondants indicated they wanted to receive massage after study completion, only $61 \%$ actually did. The primary barrier cited was cost (41\%). Of those who wanted to receive more massage therapy if cost were not an issue, the most commonly preferred treatment frequency was twice per month (43\%). Eighty-eight percent reported being willing to contribute $\$ 20$ or more toward the cost of a 60 -minute massage session, and $56 \%$ were willing to pay $\$ 30$ or more, amounts consistent with the average insurance co-pay [1].
\end{abstract}

Conclusion: In patients with chronic pain due to knee OA, most participants wanted to receive post-study massage therapy twice a month and were willing to pay an out of pocket amount comparable to a standard co-pay. These results are timely in light of recent U.S. Joint Commission requirements for hospitals to provide non-pharmacologic treatments for pain.

Keywords: Massage; Osteoarthritis; Knee; Chronic pain; Integrative medicine; Health policy; Willingness to pay; Out of pocket expense; Ideal treatment frequency; Massage survey; Intervention frequency and cost survey; IFACS

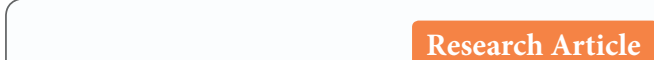

Volume 8 Issue 1 - 2017

Kristin K Jerger ${ }^{1}$, Ruth Q Wolever ${ }^{2,3 *}$ and Adam I Perlman ${ }^{4}$

${ }^{1}$ Department of Physical Medicine and Rehabilitation, University of North Carolina, Chapel Hill, USA

${ }^{2}$ Department of Physical Medicine and Rehabilitation,

Vanderbilt University Medical Center, USA

${ }^{3}$ Vanderbilt University School of Nursing, USA

${ }^{4}$ Department of Medicine, Duke University Medical Center, USA

*Corresponding author: Ruth Q Wolever, Department of Physical Medicine and Rehabilitation, Vanderbilt University Medical Center, Nashville, TN, USA,

Email: ruth.wolever@vanderbilt.edu

Received: July 09, 2017 | Published: July 24, 2017

\section{Introduction}

Chronic pain has been recognized as a significant public health problem. The Institute of Medicine estimates chronic pain affects 100 million U.S. adults [2]. Chronic pain due to osteoarthritis (OA) alone affects nearly 27 million Americans, and its prevalence is expected to rise considerably in the next several decades [3-5]. Conventional treatment options for chronic pain include pain medication, both nonsteroidal anti-inflammatory drugs (NSAIDS) and opioids, as well as treatments specific to knee OA pain such as corticosteroid injections, physical therapy, specific exercises, weight management, and joint replacement surgery [6].

Many of these treatments for chronic pain are very costly and/or have significant side-effects, including gastric distress for commonly used NSAIDS and addiction for opiates [7-11]. Even worse, despite regular treatment, many patients continue to have chronic pain [12]. The high degree of side-effects of pharmacologic treatments with incomplete efficacy have led the U.S. Joint Commission to announce the implementation of new and revised pain assessment and management standards for its accredited hospitals, effective January 1, 2018. The Elements of Performance for section LD.04.03.13 now require that, "The hospital provides nonpharmacologic pain treatment modalities" [13].
Accordingly, there is a pressing need for safe, cost-effective, treatments for pain with low side-effect profiles. With minimal side-effects and mounting evidence of treatment efficacy for chronic pain [14], massage therapy presents an attractive treatment modality to address this need. However, the primary barrier to making massage therapy adequately accessible to the chronic pain population appears to be financial.

The primary aim of this study was to collect data about actual and ideal frequency of massage therapy, real-world cost of treatment, as well as willingness and methods of paying for it, from the perspective of individuals suffering from chronic pain due to $\mathrm{OA}$ of the knee. This data was collected to help guide massage-related decisions at the policy level.

Current recommendations for pain management of knee $\mathrm{OA}$ encompass both pharmacological and non-pharmacological approaches (including manual therapy) tailored to level of pain, individual risk factors, signs of inflammation, and location and degree of structural damage $[6,15-17]$. These recommendations are reflected in the current pain management standard of The Joint Commission, the principal accrediting agency for U.S. health care organizations, which states that, "Both pharmacologic and nonpharmacologic strategies have a role in the management of 
pain." The pain management standard also specifically identifies massage therapy as a potential nonpharmacologic intervention for this purpose [18].

Similarly, a key recommendation of NIH's current National Pain Strategy is to support research on treatments that address the long-recognized link between chronic pain and mental health Two features of massage therapy that are aligned with these current national recommendations are: 1) its low side-effect profile and 2) its capacity to simultaneously treat co-morbid conditions such as chronic pain and anxiety. Massage therapy has minimal side-effects, moderate cost, and has been shown to be effective for anxiety [19-26] as well as chronic back, neck, and knee pain due to $\mathrm{OA}[27,28]$.

Thus, although massage therapy for chronic pain is not currently covered by most U.S. health insurance [29], policy changes in the near future are likely to reflect the current recommendations and accreditation standard for pain management. Having a better understanding of ideal treatment frequency for particular conditions and knowledge of patient willingness to pay for massage therapy are likely to be important for making successful policy changes.

To date, most of the relatively limited number of massage therapy implementation studies have focused on service utilization and insurance expenditures [30,31]. Those few that have asked participants about their willingness to pay for massage therapy have shown conflicting results. For instance, chronic low back pain patients in the U.S. indicated that they would only be willing to receive massage therapy if they did not have to pay out of pocket while questionnaires completed in the UK indicated that $76 \%$ of 162 cancer patients were willing to pay out of pocket for massage therapy [32]. In both studies, potential out of pocket amounts were not specified.

The current study provides data to fill the gap in knowledge about patients' ideal treatment frequency and willingness to pay for massage therapy. The study presents real-world data on services actually obtained after massage therapy study completion and their associated costs.

\section{Methods}

The following methods were reviewed and approved by the Duke University Medical Center Institutional Review Board.

\section{Data collection}

Approximately two months after completing a 52-week efficacy and dosing randomized clinical trial (RCT) of massage therapy for OA knee pain, participants were invited to complete the Intervention Frequency and Cost Survey (IFACS), a brief, validated questionnaire about their massage-seeking behavior since study completion [33]. All RCT completers who provided an email address were sent an IRB-approved email invitation to respond to the survey. The email made it clear that participation was strictly voluntary, that no compensation was offered, and that clicking on the included survey link indicated their understanding of and consent to these terms. The survey was presented using an online survey platform (Qualtrics Research Suite) that indicates whether sent emails were opened. At two-week intervals, up to two emails were re-sent to those participants with unopened emails. If potential participants who had provided email addresses did not respond to any of the three emails, or if they provided a telephone number but no email address, they received a scripted version of the email delivered live over the telephone. If potential participants did not respond after receiving three voicemails, they were excluded from the study.

\section{Data preparation and analysis}

Only two of the 119 questionnaires collected contained missing data. In both cases, the participant only responded to the first question. Because the intention of these two participants was unclear, their data was excluded from the analysis. Therefore, all analysis was done using completed questionnaires. If the survey was erroneously taken more than once, only data from the first administration was included in the analysis. For outcomes assessment, frequency counts and percentages were calculated for each response category. Independent, single tail t-tests were conducted using SAS statistical software (Cary, NC) to compare groups. Given the number of comparisons, Bonferroni corrections were made to protect against Type I error.

\section{Results}

Of those participants contacted $(n=179), 117$ completed questionnaires for a $65 \%$ response rate. Characteristics of these 117 participants are described in (Table 1). They were mostly white (92\%), women (90\%) with mean (SD) age of 57 (12.0) years and BMI of 32 (7.7). About half of them (52\%) reported being employed at the time of the study. Complete results of all survey questions are shown in Appendix 1.

Table 1: Patient Characteristics of Study Population.

\begin{tabular}{|c|c|c|}
\hline & \multicolumn{2}{|c|}{ Total Sample (N=117) } \\
\hline Characteristic & $\mathbf{M}(\mathbf{S D})$ & $\mathbf{n}(\%)$ \\
\hline Age (yrs, at Baseline) & $56.96(11.98)$ & \\
\hline BMI & $31.58(7.71)$ & \\
\hline Gender (Male) & & $12(10)$ \\
\hline Hispanic & & $0(0)$ \\
\hline Asian & & $5(4)$ \\
\hline Black or African American & & $5(4)$ \\
\hline White & & $107(92)$ \\
\hline Currently Employed (working for pay) & & $59(52)$ \\
\hline
\end{tabular}

*There were no self-identified American Indian/Alaska Native, Native Hawaiian or other Pacific Islander participants in the study.

Module 1 questions asked about massage services actually obtained. sixty-one percent $(n=71)$ reported receiving massage therapy at least once since study completion, with $75 \%$ reporting a frequency of one massage per month and 86\% reporting an average out-of-pocket amount of $\$ 60$ or more per massage session. For the $39 \%$ who did not receive massage, the primary barrier was cost (41\%). Only $3 \%$ of those who received massage 
used insurance to pay for it, with most either using the gift certificates they received for completing the parent study (58\%) or paying out of pocket (44\%).

Module 2 was used to collect participants' opinions regarding ideal cost and frequency of massage therapy sessions. Ninety-five percent $(n=111)$ responded "yes" to the question, "Would you have scheduled more sessions if cost were not an issue?" The preferred frequency of massage for this group was reported as twice per month $(43 \%$ of the $n=111$; answer options included $0,1,2,3,4$, or greater than 4 times per month). When this group was asked what they were willing to pay out of pocket for massage therapy, $88 \%$ reported being willing to pay $\$ 20$ or more per massage, and $52 \%$ indicated they would pay $\$ 30$ or more.

Those who received massage reported being willing to pay significantly more out of pocket than those who did not (Figure 1 , $\mathrm{p}<0.05$ ). In contrast, the ideal frequency of massage to manage chronic pain due to knee OA did not differ significantly between the two groups (Figure 2).

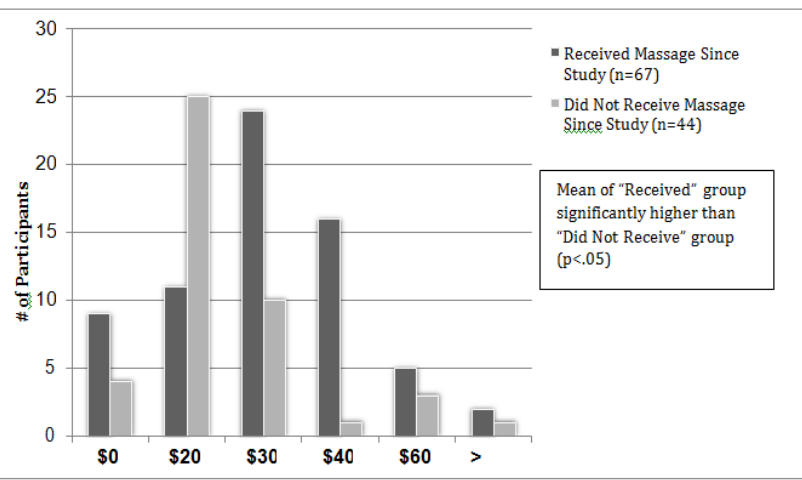

Figure 1: Willingness to pay out of pocket for massage therapy.

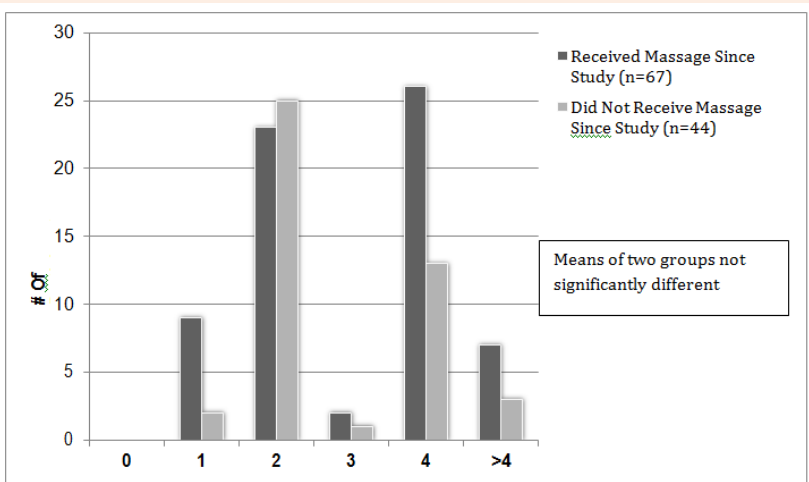

Figure 2: Ideal frequency for massage therapy (number of times per month).

\section{Discussion}

Assessments obtained with the IFACS provided findings consistent with previous trials, as well as additional information that may be useful in formulating payment policy for massage therapy. It is interesting to note that people did not expect to get massage for free. Nor did they expect to receive it every day. They seemed to have a sense of the value of massage therapy for them personally, how often they needed it, and how much it was worth to them.

Although the preferred frequency of massage was reported as twice a month ( $43 \%$ of the $n=111$ who desired more massage), the majority $(75 \%$ of $n=71)$ of those who actually received massage reported only receiving it once a month-and most paid for it using the gift certificates they received for completing the parent study. So only 30 of the 117 participants (26\%) would have received massage if they did not have gift certificates, and this was not an economically disadvantaged population. This makes sense, given that most people (88\%) reported being willing to pay $\$ 20$ or more for a 60 -minute massage, while $86 \%$ of those who paid for massage out of pocket reported paying $\$ 60$ or more for each session. Given these data, it is reasonable to assume that if massage were covered by insurance with a typical co-pay [1], almost all of our study participants (88\% willing to pay $\$ 30$ or more for a massage plus the 30 who were able to pay out of pocket) would have received massage therapy twice a month to manage their chronic pain. How this treatment would affect their overall cost of care is an important question requiring further study.

A key limitation of this study was the fact that all completers of the parent clinical trial received three free gift certificates for massage therapy at study completion. While we did track how often these gift certificates were used to pay for massage therapy, it would be ideal to gather information about cost and frequency in the absence of gift certificates. It is unclear how much this may have affected their willingness to pay or ideal frequency of massage therapy. In addition, because the surveyed population was drawn from completers of an RCT, the results cannot be generalized beyond the population represented in the RCT. This population is limited to those who have received massage therapy before.

A key strength of using the IFACS for this study is that the IFACS was specifically designed to be administered following an RCT. Thus, because all participants in this study also completed the EMBARK clinical trial of massage for chronic pain due to OA which collected data about pain, function, and quality of life over twelve months, our findings can be linked to this data once analysis for the parent trial is complete. For instance, it would be interesting to determine whether there are associations between average improvement in pain scores, quality of life, and mental health measures obtained in the RCT and whether or not participants received massage therapy post-study.

As the demand for nonpharmacologic treatments for chronic pain increases, as evidenced by the Joint Commission's requirement for hospitals to provide such by January 2018, the evidence base for massage therapy for chronic pain has become more salient. In response to this demand, the center of gravity of massage therapy studies has moved from basic efficacy trials to more translational research, testing detailed dosing protocols to optimize clinical outcomes for specific conditions [34]. One 
barrier to progressing along this translational pathway to realworld conditions is developing effective payment models that include massage therapy, allowing access to more people who suffer from chronic pain. It is our hope that the data presented here as well as the tool used to collect them (IFACS) will be useful for developing effective massage therapy payment and delivery models [35].

\section{Conclusion}

In patients with OA knee pain who participated in a RCT on massage therapy, most participants wanted post-study massage therapy twice a month and were willing to pay an out of pocket amount comparable to a standard co-pay. Future research should explore payment models that facilitate access to massage therapy for patients with chronic pain.

\section{References}

1. http://meps.ahrq.gov/mepsweb/data_files/publications/st427/ stat427.pdf

2. http://www.nap.edu/catalog.php?record_id=13172

3. Cameron KL, Hsiao MS, Owens BD, Burks R, Svoboda SJ (2011) Incidence of physician-diagnosed osteoarthritis among active duty United States military service members. Arthritis Rheum 63(10): 2974-2982.

4. Dominick KL, Golightly YM, Jackson GL (2006) Arthritis prevalence and symptoms among US non-veterans, veterans, and veterans receiving Department of Veterans Affairs Healthcare. J Rheumatol 33(2): 348-354.

5. Lawrence RC, Felson DT, Helmick CG, Arnold LM, Choi H, et al. (2008) Estimates of the prevalence of arthritis and other rheumatic conditions in the United States. Part II. Arthritis Rheum 58(1): 2635.

6. Hochberg MC, Altman RD, April KT, Benkhalti M, Guyatt G, et al. (2012) American College of Rheumatology 2012 recommendations for the use of nonpharmacologic and pharmacologic therapies in osteoarthritis of the hand, hip, and knee. Arthritis Care Res (Hoboken): 64(4): 465-474.

7. Baser O, Xie L, Mardekian J, Schaaf D, Wang L, Joshi AV (2014) Prevalence of diagnosed opioid abuse and its economic burden in the veterans health administration. Pain Pract 14(5): 437-445.

8. Blieden M, Paramore LC, Shah D, Ben-Joseph R (2014) A perspective on the epidemiology of acetaminophen exposure and toxicity in the United States. Expert Rev Clin Pharmacol 7(3): 341-348.

9. Edlund MJ, Austen MA, Sullivan MD, Martin BC, Williams JS, et al. (2014) Patterns of opioid use for chronic noncancer pain in the Veterans Health Administration from 2009 to 2011. Pain 155(11):2337-2343.

10. Naesdal J, Brown K (2006) NSAID-associated adverse effects and acid control aids to prevent them: a review of current treatment options. Drug Saf 29(2): 119-132.

11. Rozet I, Nishio I, Robbertze R, Rotter D, Chansky H, et al. (2014) Prolonged opioid use after knee arthroscopy in military veterans. Anesth Analg 119(2): 454-459.

12. Richmond J, Hunter D, Irrgang J, Jones MH, Levy B, et al. (2009) Treatment of osteoarthritis of the knee (nonarthroplasty) J Am Acad Orthop Surg 17(9): 591-600.
13. Joint Commission (2017) Joint Commission Enhance Pain Assessment and Management Requirements for Accredited Hospitals The Joint Commission Perspectives: The Official Newsletter of the Joint Commission 37(7).

14. Crawford C, Boyd C, Paat CF, Price A, Xenakis L, et al. (2016) The Impact of Massage Therapy on Function in Pain Populations-A Systematic Review and Meta-Analysis of Randomized Controlled Trials: Part I, Patients Experiencing Pain in the General Population. Pain Med pnw099.

15. Brown KM, Hirshon JM, Alcorta R, Weik TS, Lawner B, et al. (2014) The implementation and evaluation of an evidence-based statewide prehospital pain management protocol developed using the national prehospital evidence-based guideline model process for emergency medical services. Prehosp Emerg Care 18(Suppl 1): 45-51.

16. Jordan KM, Arden NK, Doherty M, Bannwarth B, Bijlsma JW, et al. (2003) EULAR Recommendations 2003: an evidence based approach to the management of knee osteoarthritis: Report of a Task Force of the Standing Committee for International Clinical Studies Including Therapeutic Trials (ESCISIT) Ann Rheum Dis 62(12): 1145-1155.

17. McAlindon TE, Bannuru RR2, Sullivan MC2, Arden NK3, Berenbaum $F$, et al. (2014) OARSI guidelines for the non-surgical management of knee osteoarthritis. Osteoarthritis Cartilage 22(3): 363-388.

18. https://www.jointcommission.org/issues/

19. Braun LA, Stanguts C, Casanelia L, Spitzer O, Paul E, et al. (2012) Massage therapy for cardiac surgery patients--a randomized trial. J Thorac Cardiovasc Surg 144(6): 1453-1459.

20. Field T, Ironson G, Scafidi F, Nawrocki T, Goncalves A, et al. (1996) Massage therapy reduces anxiety and enhances EEG pattern of alertness and math computations. Int J Neurosci 86(3-4): 197-205.

21. Lin ML, Tsang YM, Hwang SL (1998) Efficacy of a stress management program for patients with hepatocellular carcinoma receiving transcatheter arterial embolization. J Formos Med Assoc 97(2): 113117.

22. Nerbass FB, Feltrim MI, Souza SA, Ykeda DS, Lorenzi-Filho G (2010) Effects of massage therapy on sleep quality after coronary artery bypass graft surgery. Clinics (Sao Paulo): 65(11): 1105-1110.

23. Noto Y, Kitajima M, Kudo M, Okudera K, Hirota K (2010) Leg massage therapy promotes psychological relaxation and reinforces the firstline host defense in cancer patients. J Anesth 24(6): 827-831.

24. Noto Y, Kudo M, Hirota K (2010) Back massage therapy promotes psychological relaxation and an increase in salivary chromogranin $\mathrm{A}$ release. J Anesth 24(6): 955-958.

25. Sharpe PA, Williams HG, Granner ML, Hussey JR (2007) A randomised study of the effects of massage therapy compared to guided relaxation on well-being and stress perception among older adults. Complement Ther Med 15(3): 157-163.

26. Wentworth LJ, Briese LJ, Timimi FK, Sanvick CL, Bartel DC, et al. (2009) Massage therapy reduces tension, anxiety, and pain in patients awaiting invasive cardiovascular procedures. Prog Cardiovasc Nurs 24(4): 155-161.

27. Perlman AI, Sabina A, Williams AL, Njike VY, Katz DL (2006) Massage therapy for osteoarthritis of the knee: a randomized controlled trial. Arch Intern Med 166(22): 2533-2538.

28. Sherman KJ, Cook AJ, Wellman RD, Hawkes RJ, Kahn JR,etb al. (2014) Five-week outcomes from a dosing trial of therapeutic massage for chronic neck pain. Ann Fam Med 12(2): 112-120. 
29. https://www.cigna.com/healthwellness/hw/medical-topics/ massage-therapy-aa85228spec

30. Lafferty WE, Tyree PT, Bellas AS, Watts CA, Lind BK, et al. (2006) Insurance coverage and subsequent utilization of complementary and alternative medicine providers. Am J Manag Care 12(7): 397 404.

31. Lind BK, Lafferty WE, Tyree PT, Diehr PK, Grembowski DE,(2007) Use of complementary and alternative medicine providers by fibromyalgia patients under insurance coverage. Arthritis Rheum 57(1): 71-76.

32. Sherman KJ, Cherkin DC, Connelly MT, Erro J, Savetsky JB, et al (2004) Complementary and alternative medical therapies for chronic low back pain: What treatments are patients willing to try? BMC Complement Altern Med 4: 9.

33. Jerger K, Wolever R, Perlman A (2017) Psychometric Properties of the Intervention Frequency and Cost Survey (IFACS) Int J Complement Alt Med 5(1): 00144.

34. Perlman AI, Ali A, Njike VY, Hom D, Davidi A, et al. (2012) Massage therapy for osteoarthritis of the knee: a randomized dose-finding trial. PLoS One 7(2): e30248.

35. http://effectivehealthcare.ahrq.gov/index.cfm/what-iscomparative-effectiveness-research1/ 